\title{
BABESIA DIVERGENS : AN ELISA WITH SOLUBLE PARASITE ANTIGEN FOR MONITORING THE EPIDEMIOLOGY OF BOVINE BABESIOSIS
}

\author{
CHAUVIN A.*, L'HOSTIS M.*,****, VALENTIN A.**, PRECIGOUT E.***, CESBRON-ZEGGANE N.* \& GORENFLOT A.***
}

\section{Summary :}

An enzyme linked immunosorbent assay (ELISA) for bovine babesiosis caused by Babesia divergens was developed to analyse the evolution of the serological status of cattle living in an enzootic area. The antigen used was a soluble extract of $B$. divergens obtained from in vitro culture. Specificity, evaluated with negative sera, was $96,6 \%$. The ELISA was compared to indirect immunofluorescence analysis (IFA) on naturally or experimentally infected animals. It appeared that IFA was positive for at least seven or eight weeks; on the contrary, B. divergens-specific antibodies were only transitorily detected by ELISA. Furthermore, the ELISA was more sensitive than the IFA for the detection of post-infection antibody increases, particularly when infection-pressure was low. These results suggest that IFA and ELISA could be complementary tools in epidemiological surveys; indeed, this ELISA could be the most efficient tool to detect new infections in cohort monitoring.

KEY WORDS : ELISA. kinetic of antibodies. Babesia divergens. cattle. MOTS CLÉS : ELISA. cinétique des anticorps. Babesia divergens. Bovins.
Résumé : BABESIA DIVERGENS : UN ELISA UTILISANT UN ANTIGÈNE PARASITAIRE SOLUBLE POUR LE SUIVI ÉPIDÉMIOLOGIQUE DE LA BABESIOSE BOVINE Un ELISA pour la babésiose bovine à Babesia divergens a été développé pour analyser le statut sérologique de bovins vivant dans une zone d'enzootie. L'antigène utilisé est constitué d'un extrait hydrosoluble de B. divergens obtenus par culture in vitro. La spécificité de la technique, évaluée sur des sérums d'animaux négatits, est de $96,6 \%$. Par ailleurs, I'ELISA a été comparé à l'immunofluorescence indirecte (IFI) sur des animaux infectés naturellement ou expérimentalement. Les anticorps spécifiques de B. divergens sont détectés pendant au moins sept à huit semaines par IFI, alors qu'ils ne sont mis en évidence que transitoirement par ELISA. Toutefois, I'ELISA semble plus sensible que l'IFI pour la détection des augmentations d'anticorps après infection, notamment quand la pression d'infection est faible. Ces résultats permettent d'envisager l'emploi de l'IFI et de I'ELISA comme deux outils complémentaires lors d'enquête épidémiologique. Plus particulièrement, cet ELISA est probablement l'outil le plus efficace pour détecter les infections lors d'un suivi de cohorte.

\section{INTRODUCTION}

M ost cases of the bovine babesiosis in western Europe are caused by the intraerythrocytic development of the parasite Babesia divergens (Telford et al., 1993). In order to improve knowledge about babesiosis, epidemiological and serological surveys have to be made on large numbers of animals and for long periods of time. Until now, the serological response of cattle to $B$. divergens infection was mostly monitored by indirect immunofluorescence analysis (IFA) (Adam and Blewett, 1978;

\footnotetext{
* Laboratoire de Parasitologie, École Nationale Vétérinaire de Nantes, CP 3013, F-44087 Nantes Cedex 03.

** Laboratoire d'Immunologie et Parasitologie, UFR des Sciences Pharmaceutiques et Biologiques, 15 avenue Charles Flahault, F-34060 Montpellier Cedex.

*** Laboratoire de Biologie Cellulaire, UFR des Sciences Pharmaceutiques et Biologiques, 15 avenue Charles Flahault, F-34060 Montpellier Cedex.

***** Laboratoire de Gestion de la Santé Animale, INRA - Ecole Nationale Vétérinaire, CP 3013, F-44087 Nantes Cedex 03.

Correspondance : Alain Chauvin, Laboratoire de Parasitologie, Ecole Nationale Vétérinaire de Nantes, CP 3013, F-44087 Nantes Cedex 03. Tel : 40687698 - Fax : 40687751.
}

Taylor et al., 1982; Gern et al., 1988; Losson and Lefèvre, 1989). Although IFA is a well adapted method for the determination of the incidence of babesiosis in a herd, it is a time-consuming and subjective method (Gray and Kaye, 1991). Furthermore, the disadvantages of IFA are amplified when the survey consists of a cohort study for one or two years. For such an epidemiological analysis, a semi-automated test is necessary, and the test has to be performed with an easy-to-produce antigen. Routine diagnosis of Babesia bovis babesiosis with an enzyme linked immunosorbent assay (ELISA) using a defined parasite antigenic fraction has been described (Waltisbuhl et al., 1987). For B. divergens, ELISA requires parasitized erythrocytes obtained from live animals (Purnell et al., 1976; Gray and Kaye, 1991). The previous description of a long term in vitro culture for $B$. divergens has allowed us to produce purified parasites (Gorenflot et al., 1991; Becuwe et al., 1992). The purpose of the present study was to develop an ELISA using these purified parasites as a source of antigen. In order to test the performance of this serological tool in an epidemiological survey, the ELISA was compared to the IFA. 


\section{Animal number}

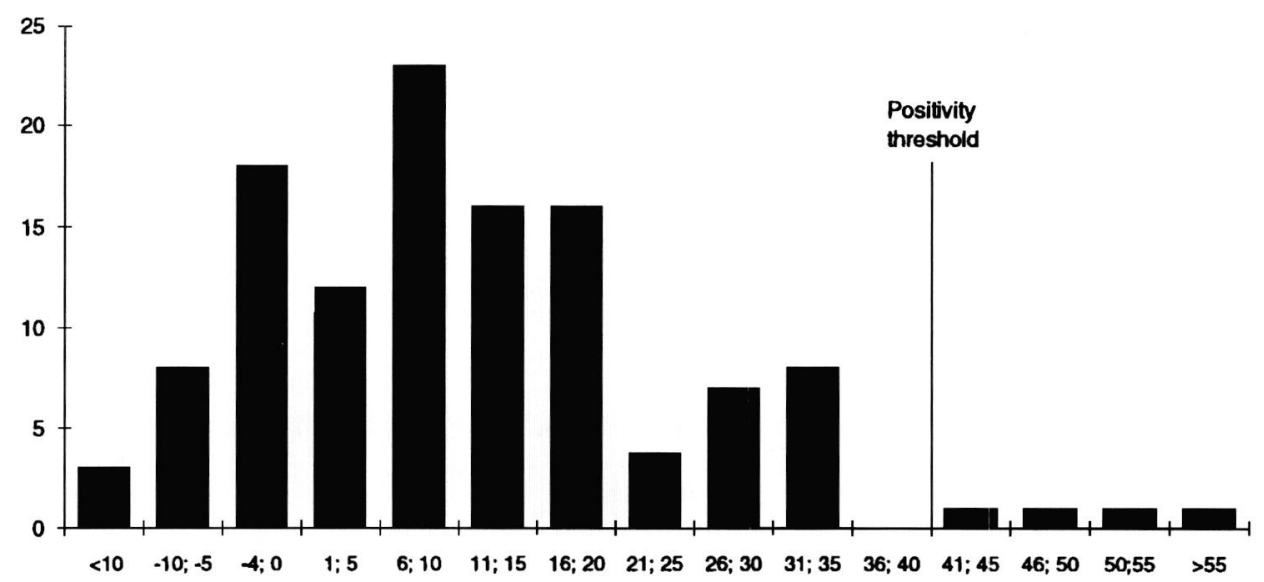

Fig. 1. - Antibody mean of the negative sera, and evaluation of positivity threshold.
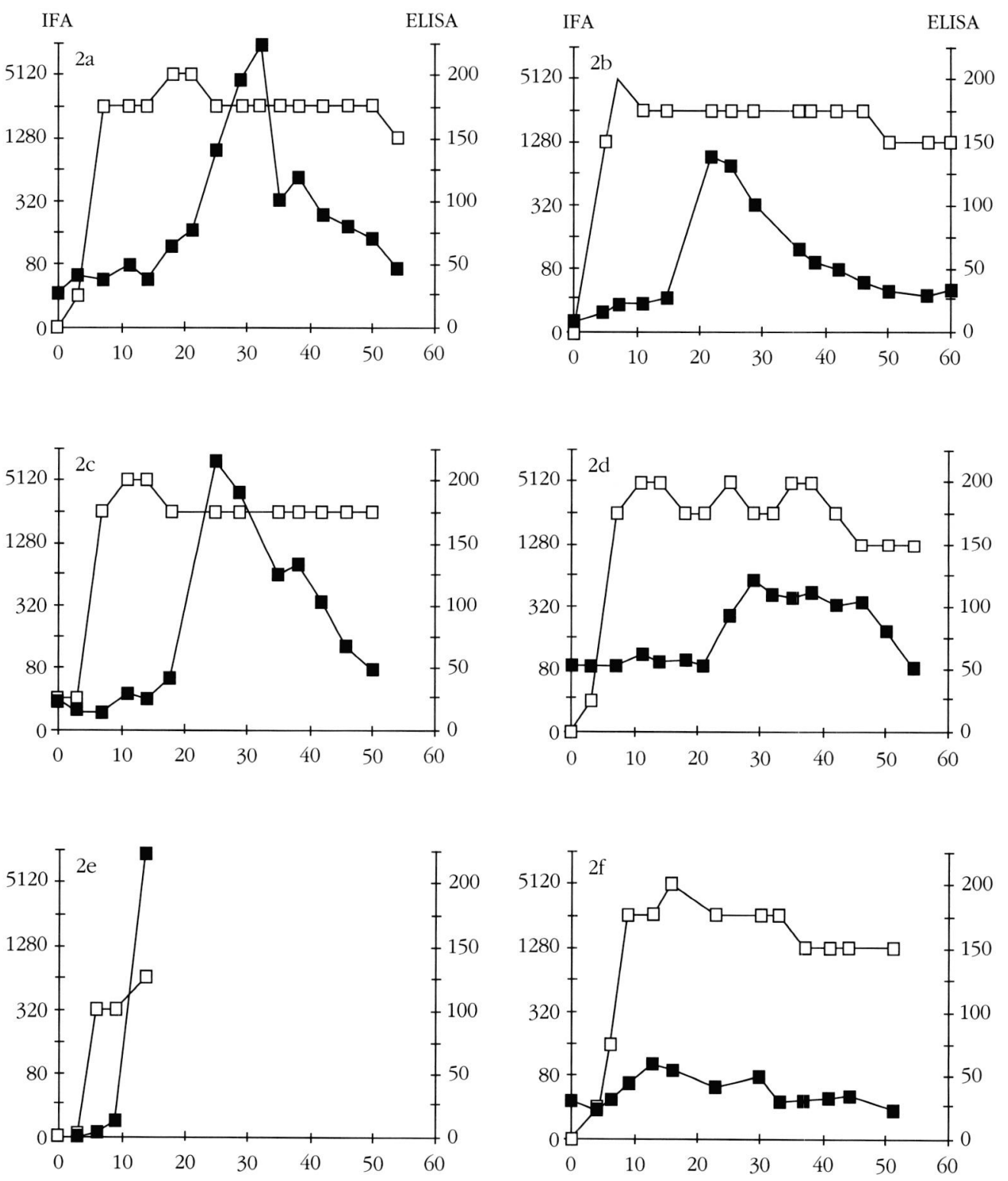

Fig. 2. - Kinetics of antibodies (ELISA AbR : $\mathbf{\square}$, and IFA reciprocal titer : $\square$ ) of six experimentally infected animals. 


\section{MATERIAL AND METHODS}

ANIMALS AND SERA

N egative sera were obtained from seven calves maintained in a tick-free cowshed since birth and from 112 cattle of "Belle Ile en Mer", an area without $B$. divergens bovine babesiosis. The kinetics of antibodies were followed in six animals which were seronegative by IFA at the beginning of the study. They were infected by intravenous injection of $10^{11}$ bovine red cells parazited with $B$. divergens "isolate Rouen, 1987" (Gorenflot et al., 1991). The kinetics of antibodies were also followed in 12 animals from two herds known to be infected by $B$. divergens; of those 12 animals, blood was obtained monthly for 10 months by jugular venipuncture, and sera were aliquoted and stored at $-20^{\circ} \mathrm{C}$ until use.

Cross reactions were tested with positive sera against Fasciola bepatica (enzootic in the survey area) which has been suspected to interfere with Babesia infection (Fagbemi et al., 1985). Cross reactions were also studied for other bovine tick-borne parasites, namely B. bovis, B. bigemina, Anaplasma marginale, Theileria mutans and Cowdria ruminantium (Dr. Camus, CIRAD-EMVT).

\section{TICK NUMERATION}

Data about the infestation level of the cattle by Ixodes ricinus (vector of $B$. divergens) were recorded each month during the same period by palpation with the palm of the hand and the fingers through the hair on one axilla of each animal (L'Hostis et al., 1995). Data are expressed as mean tick number per animal.

\section{IFAT AND ELISA}

For both IFA and ELISA, the antigen was prepared from the same isolate : B. divergens "Rouen 1987" (Gorenflot et al., 1991).

For IFA, the parasite was maintained by syringe passage in gerbils (Lewis and Williams, 1979), and parasitized blood (parasitaemia : $20 \%$ ) was prepared and treated as previously described (Gray and Harte, 1985). The bovine sera were diluted in phosphate buffered saline (PBS) pH $7.2(\mathrm{NaCl}: 136.9 \mathrm{mM}, \mathrm{KCl}$ : $2.7 \mathrm{mM}, \mathrm{KH}_{2} \mathrm{PO}_{4}: 1.47 \mathrm{mM}, \mathrm{Na}_{2} \mathrm{HPO}_{4}: 8 \mathrm{mM}$ ) from $1: 40$ to $1: 5120$. Fluorescein isothiocyanate-labelled rabbit anti-bovine immunoglobulins (IgG $(\mathrm{H}+\mathrm{L})$, Byosis, France) diluted in PBS (1:100) were used to detect specific antibodies.

For ELISA, the antigen was prepared from $B$. divergens in vitro culture in human erythrocytes maintained in RPMI supplemented with $10 \%$ human serum (Gorenflot et al., 1991). Free parasites were obtained as previously described (Becuwe et al., 1993). Collected parasites were submitted to ten freeze-thawing cycles, centrifuged $(4,000 \mathrm{~g}, 15 \mathrm{~min}$ ) and the supernatant, containing soluble proteins, was used as antigen. Microplates (96-wells, Microwell Nunc) were coated overnight at $37^{\circ} \mathrm{C}$ with this antigen diluted to a protein content of $1 \mu \mathrm{g} / \mathrm{ml}$ in $0.1 \mathrm{M} \mathrm{pH} 9.6$ sodium carbonate buffer $(100 \mu \mathrm{l} /$ well). After washing three times ( 5 min per wash) with PBS $0.05 \%$ Tween 20 (PBST), the plates were saturated with $150 \mu \mathrm{l}$ of $5 \%$ Rabbit serum in PBST (PBST/R) at $37^{\circ} \mathrm{C}$ for $30 \mathrm{~min}$. After dilution in PBST/R, bovine sera were distributed in duplicate $(100 \mu \mathrm{l} /$ well) and the plates incubated at $37^{\circ} \mathrm{C}$ for $15 \mathrm{~min}$. After washing three times in PBST, peroxidase-labelled rabbit anti-bovine immunoglobulins (IgG $(\mathrm{H}+\mathrm{L})$, Byosis, France) were added to each well and the plates were incubated for $45 \mathrm{mn}$ at $37^{\circ} \mathrm{C}$. After preliminary studies, we used a serum dilution of $1: 200$ and a conjugate dilution of $1: 3000$. After washing twice in PBST and twice in PBS, $100 \mu \mathrm{l}$ of peroxidase substrate $(0.5 \mathrm{mg} / \mathrm{ml}$ ortho-phenylenediamine (SIGMA, France) in sodium citrate buffer $0.1 \mathrm{M}, \mathrm{pH} 5$ with $0.83 \mu \mathrm{l} / \mathrm{ml} 30 \% \mathrm{H}_{2} \mathrm{O}_{2}$ ) were added to each well. After incubation for $30 \mathrm{~min}$ at $37^{\circ} \mathrm{C}$, the reaction was stopped by addition of $50 \mu \mathrm{l} 2.5 \mathrm{M}$ $\mathrm{H}_{2} \mathrm{SO}_{4}$ per well and the plates were read at $492 \mathrm{~nm}$ with an ELISA automat (Titertek, Multiscan MC, Helsinki, Finland). Results are presented as specific antibodies mean rate (AbR) determined as follows :

\footnotetext{
(sample mean OD) - (negative controls mean OD)

$\mathrm{AbR}=1$ ( $\times 100$

(positive controls mean OD) - (negative controls mean OD)
}

Mean optical density (OD) was obtained from the values read in two wells. Positive control sera consisted of a pool of sera obtained from three cows experimentally infected with $B$. divergens "Rouen 1987" four to eight weeks before (IFA titer $>1$ : 2500), negative control sera consisted of a pool of sera obtained from four three-year old oxen raised in a tick-free cowhouse.

\section{RESULTS}

\section{SPECIFICITY OF THE ELISA TEST}

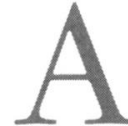

bR of the negative sera (119 animals) are summarized in Figure 1. To minimize lack of specificity, the threshold of the ELISA test was evaluated as $\mathrm{AbR}=40 \%$. In this case, we observed four false positive and specificity is $96,6 \%$ (standard error: $93,3 \%-99,9 \%, \mathrm{p}<0.05)$. The AbR of positive sera against B. bovis, B. bigemina, A. marginale, T. mutans, C. ruminantium, $F$. hepatica were under the positive threshold (data not shown). 


\section{Mean tick number}

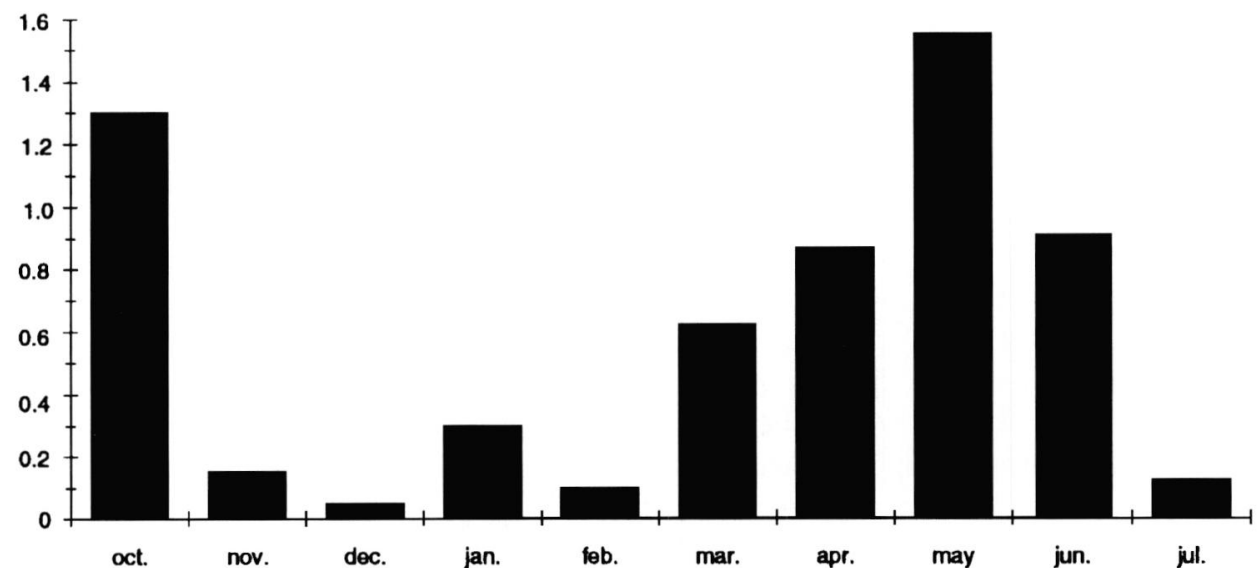

Fig. 3. - Mean tick number on cattle during the ten months. Ticks were counted on sampling day (once a month)
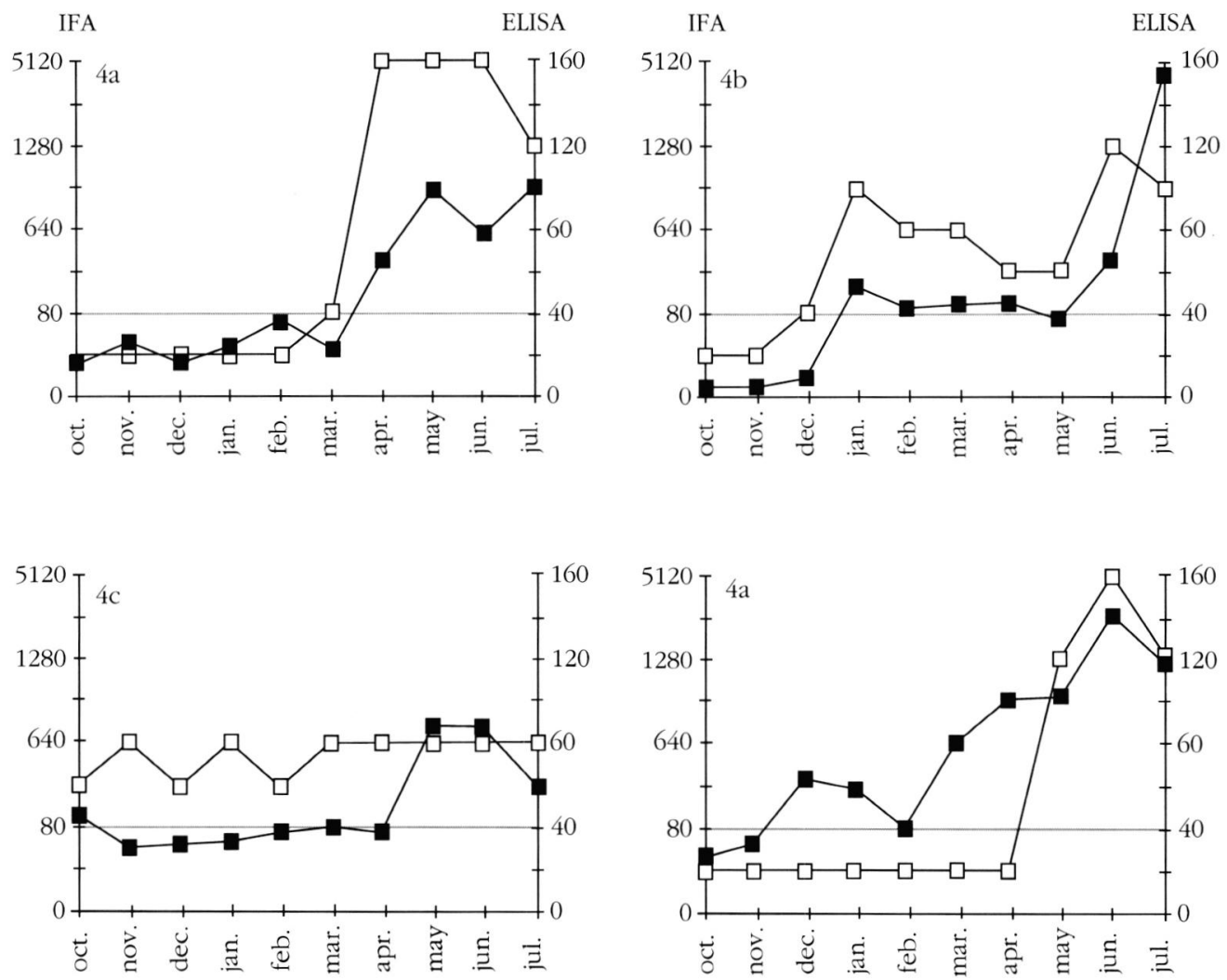

Fig. 4. - Comparison of ELISA (AbR : $\mathbf{}$ ) and IFA (reciprocal titer : $\square$ ) for the detection of $B$. divergens-specific antibodies Animals were sampled once monthly, AbR was calculated as indicated in the materials and methods section. Each chosen curves represent a typical aspect of the results obtained : a-b : apparent correlation between ELISA and IFA : one seroconversion in spring (a) and two seroconversions: in spring and at the end of the autumn (b); c-d : ELISA was more sensitive than IFA : ELISA detected a seroconversion that was not evident by IFA (c), ELISA detect two seroconversions in spring and at the end of the autumn while IFA detected only one in spring when tick pressure was high (d). 
KINETIC COMPARISON BETWEEN THE RESULTS OBTAINED WITH THE TWO METHODS (IFA AND ELISA)

Antibody kinetics detected by ELISA or IFA of experimentally infected animals are shown on Figure 2. With the ELISA, the AbR increased in week 2 (Fig. 2e, 2f) post-infection (WPI 2) or in WPI 3 (Fig. 2a, 2b, 2c). AbR rose to a peak value between WPI 2-3 and 5 , then decreased rapidly. AbR increases were between $29 \%$ (Fig. 2f) and $180 \%$ (Fig. 2a, 2c), and AbR were positive for a period of 21 (Fig. 2f) to 36 (Fig. 2a) days. For one animal (Fig. 2d), the AbR was over the threshold before infection (false positive) but we also observed an AbR increase of $40 \%$ to $60 \%$ in WPI 3 and 4 and AbR returned to baseline in 29 days. In contrast, in all cases, IFA became positive in WPI 1 and the antibody level remained stable for at least 7-8 weeks.

To evaluate infection pressure on naturally infected animals, the number of ticks harvested on each animal was recorded on each sampling day, the results obtained are summarized in Figure 3. The presence of two peaks was clearly demonstrated, one in October, the other one, higher, in spring. The ELISA and IFA kinetics of 12 animals bred in these farms, gave different patterns (Fig. 4). For five cows, ELISA and IFA gave very similar results for the kinetics and number of antibody increases (one antibody increase in spring : Fig. 4a, and two antibody increases, one in winter followed by a higher one in spring: Fig. 4b). For six cows, ELISA detected antibody increases that were not revealed by IFA : in spring for two cows (Fig. 4c) and, finally in autumn or winter for four cows (Fig. 4d).

\section{DISCUSSION}

I $\mathrm{n}$ this study, we used an in vitro culture-derived antigen. Other kinds of antigens have been tested in ELISA, such as bovine or gerbil Babesia divergens parasitized erythrocytes (Purnell et al., 1976; Gray and Kaye, 1991), but they require either the maintenance of splenectomized cattle or the sacrifice of gerbils (Gray and Kaye, 1991).

The threshold of our ELISA was determined by evaluating the background response of negative samples. This relatively high background could be explained by the presence of some non-specific antigens in the parasite extract as observed by Valentin et al. (1993) using a radiolabelled immunoprecipitation method. However, with a threshold of $40 \%$, the specificity of the ELISA test was $96,6 \%$ and positive sera against other pathogens, particularly other Babesia species, showed no cross reactions. However, because of the transitory detection of $B$. divergens-specific antibodies in ELISA, kinetic studies of experimentally infected animals are needed to produce further conclusions about these cross-reactions.

Comparison of the kinetics of antibody level in ELISA and IFA showed that antibody was detected earlier in IFA than in ELISA, and that the recognition of antibodies is shorter-lived in ELISA than in IFA. Bidwell et al. (1978) observed a similar transitory increase in antibody level using an ELISA with a similar soluble antigen prepared from $B$. divergens infected erythrocytes and the IFA response was similar to that observed in the present study. Using an immunoprecipitation method with radiolabelled parasite extracts, Gorenflot et al. (1991) observed an early and persistent antibody response from WPI 1 to 22 . The origin of the discordance between these three serological methods could be explained by the antigens used: the immunoprecipitation antigen was a Triton X100soluble parasite extract, the ELISA antigen was watersoluble parasite material and antibodies detected by IFA were mostly directed against parasite membranes. Furthermore, Bose et al. (1994) demonstrated by using western blotting that some antigens of Babesia caballi were only recognized during early infection in horses. Further studies are needed to characterize the antigens of $B$. divergens detected in this ELISA test and to compare the different antigens commonly used. The short persistence of antibodies suggests that sensitivity of our ELISA in a diagnostic test will be lower than IFA since it could only detect the antibodies between the second or third to the sixth or seventh week after infection.

In comparison, in naturally infected animals, the ELISA test detected antibodies that were not revealed by IFA in four animals. In these four cases, IFA and ELISA were similar only in spring, when infection pressure (as revealed by tick number) was high; on the other hand, ELISA alone detected the seroconversion in winter when cattle were occasionally on the pastures and when tick pressure was lower. These facts support the hypothesis of a higher sensitivity of the ELISA in the detection of infection when infection pressure was low.

These data suggest that ELISA and IFA are complementary tools in epidemiological surveys. The IFA allows the determination of the immunological status of an infected or naive herd. Our ELISA cannot discriminate between naive and previous infected animals, however it can detect the time of infection and could probably detect several infections during a grazing season. Therefore, this ELISA is a new epidemiological tool which will be more efficient in a cohort 
monitoring during an epidemiological survey. In such a study, blood samples must be taken at least every three to four weeks which is the period when ELISA is positive after an infection, and an antibody increase of $25 \%$ will indicate a new infection.

\section{ACKNOWLEDGEMENTS}

W e thank Mrs. Marchand and Roux (Ecole Nationale Vétérinaire, Nantes) and Mrs Savoie and Ferré (Laboratoire départemental vétérinaire, Sarthe) and $\mathrm{Mr}$ Chatelier (Fédération des Groupements de Défense Sanitaire, Sarthe) for their efficient technical assistance. We thank the farmers for their helpful cooperation. We thank also Dr. Camus (CIRAD-EMVT, Pointe-à-Pitre) and Dr. Lebigre (Veterinary surgeon, Belle Ile en Mer), for their samples. This work was partly supported by the Ministère de l'Agriculture et de la Pêche (Laboratoire de Parasitologie et Laboratoire de gestion de la santé animale, Ecole Nationale Vétérinaire de Nantes) and by grants from Rhône-Mérieux S.A.

\section{REFERENCES}

Adam K.M.G. \& BlewetT D.A. A serological survey for Babesia in cattle in Scotland. II. The occurence of antibody in the population and the distribution of infected herds. Annals of Tropical Medicine and Parasitology, 1978, 5, 417- 428 .

Becuwe P., Slomianny C., Valentin A., Schrével J., Camus D. \& Dive D. Endogenous superoxide dismutase activity in two Babesia species. Parasitology Research, 1992, 105, 177-182.

Bidwell D.E., Turp P., Joyner L.P., Payne R.C. \& Purnell R.E. Comparisons of serological tests for Babesia in British cattle. Veterinary Record, 1978, 103, 446-449.

Böse R., Peymann B. \& Barbosa I.P. Identification of diagnostic antigens for South American Babesia caballi infections. International Journal for Parasitology, 1994, 24, 255-258.

Fagbemi B.O., Christensen N.O. \& NANSEn P. Suppression of Babesia microti infection in mice concurrently infected with Fasciola bepatica. Veterinary Parasitology, 1985, 17, $101-110$

Gern L., Kindler A. \& Brossard M. Annual evolution of cattle immunity against Babesia divergens in Northern Switzerland. Preventive Veterinary Medicine, 1988, 6, 916.

Gorenflot A., Brasseur P., Précigout E., L'Hostis M., Marchand A. \& SChrével J. Cytological and immunological responses to Babesia divergens in differents hosts: ox, gerbil, man. Parasitology Research, 1991, 77, 3-12.
Gray J.S. \& Harte L.N. An estimation of the prevalence and economic importance of clinical babesiosis in the republic of Ireland. Irish veterinary Joumal, 1985, 39, 75-78.

Gray J.S. \& Kaye B. Studies on the use of gerbil-derived Babesia divergens antigen for diagnosis of bovine babesiosis. Veterinary Parasitology, 1991, 39, 215-224.

LEWIS D. \& Williams H. Infection of the Mongolian gerbil with the cattle piroplasm Babesia divergens. Nature, 1979, 278, 170.

L'Hostis M., Diarra O. \& Seegers H. Sites of attachment and density assessment of female Ixodes ricinus (Acari : Ixodidae) on dairy cows. Experimental and applied acarology, 1994, 18, 681-689.

Losson B. \& LeFÈve F. La babésiose bovine en Belgique Une enquête sérologique en zone d'endémie. Annales de Médecine Vétérinaire, 1989, 133, 421-426.

Purnell R.E., Hendry D.J., Bidwell. P. \& Turp P. Microplate enzyme linked immunosorbent assay for antibody to Babesia divergens in cattle. Veterinary Record, 1976, 99, 102.

Telford S.R., Gorenflot A., Brasseur P. \& Spielman A. Babesia infections in bumans and wildlife in Parasitic Protozoa, $2^{\mathrm{e}}$ ed, Vol V, Kreir (Eds), Academic Press, INC, San Diego USA. 1993, pp 1-47.

TAYlor S.M., Kenny J. \& STRAIn A. The distribution of Babesia divergens infection within the cattle population of Northern Ireland. British Veterinary Journal, 1982, 138, 384-392.

Valentin A., Précigout E., L'Hostis M., Carcy B., Gorenflot A. \& SCHrÉvel J. Cellular and humoral responses induced in cattle by vaccination with Babesia divergens culturederived exoantigens correlate with protection. Infection and Immunity, 1993, 61, 734-742.

Waltisbuhl B.V., Goodger I.G., Commins M.A. \& Mahonney D.F. An enzyme linked immunosorbent assay to diagnose Babesia bovis infection in cattle. Parasitology Research, 1987, 73, 126-131. 